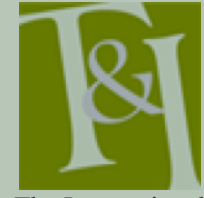

The International Journal for Translation \& Interpreting Research trans-int.org

\title{
Back translation as a documentation tool
}

\author{
Jiyoung Son \\ Independent researcher \\ jiyoung.sonn@gmail.com
}

DOI: $10.12807 / t i .110202 .2018 . a 07$

\begin{abstract}
Using back translation as a quality assessment tool in multilingual survey research is now deemed obsolete or on its way to becoming so, although it is still widely practiced. This paper will argue that back translation may be still useful as a documentation tool, not as a quality control tool. To support this premise, a review of literature that uses back translation to illustrate inevitable differences between the source and the target text is provided. This paper proposes a baseline for using back translation as a documentation tool, using examples of "good" and "bad" back translations. The value of using back translation is further demonstrated using examples from recent studies that integrated back translation into their documentation. This less-discussed use of back translation in questionnaire translation methodology merits the attention of translators and researchers. Although the utility of back translation as a quality control tool is deemed obsolete, it still has the potential for useful application as a documentation tool.
\end{abstract}

Keywords: back translation, documentation, questionnaire translation

\section{Introduction}

Back translation, or translation of a translated text back into its original language, has been used in cross-cultural survey research over the past 50 years, primarily as a translation quality assessment tool. It was historically the first linguistic quality control technique introduced to cross-cultural research and has been considered a standard translation procedure for a long time (Dept, Ferrari, \& Halleux, 2017; Harkness, Villar, \& Edwards, 2010). For example, Douglas and Craig (2007) noted that among the 45 articles published in the Journal of International Marketing between 1997 and 2005 that reported surveys using multiple languages, 34 of them $(75 \%)$ used back translation as a primary quality assessment method. In the health research field, Acquadro and her colleagues (Acquadro, Conway, Hareendran, \& Aaronson, 2008) found that 14 out of 15 distinctive translation guidelines that they identified through extensive review of clinical research references published between 1966 and 2005 included back translation as one of the recommended components for multistep translation approaches. Researchers relied on back translation because they believed comparing the original source language version and the back-translated version allowed them to make inferences about the quality of the translation (Brislin, 1970, 1984), or simply because it was the most commonly used method to "ensure" equivalency between the source and the target text (see Chidlow, Plakoyiannaki, \& Welch, 2014, for common vocabularies used to justify the use of back translation). 
However, the efficacy of back translation as a translation quality testing tool has been questioned in the past decades. It is argued that quality translation of a survey instrument would never be achieved through this indirect assessment because the linguistic appropriateness of the translated text itself would have no chance to be addressed through this method. Back translation assessment is unable to detect whether the translation is simple and clear to understand, suitable for intended target respondents, or sounds natural in the target language (Harkness, 2003; Harkness \& Schoua-Glusberg, 1998; Harkness, Villar, Kephart, Behr, \& Schoua-Glusberg, 2009). More importantly, back translation is not an appropriate assessment tool according to the recent shift in paradigm defining good practice in survey questionnaire translation. Survey translation is no longer a process of adopting the instrument from the source language directly into a target language to ask the same question, but a process of adapting the instrument into a target language and culture to measure the same construct by achieving functional equivalence (Behr, 2016; Harkness, Dorer, \& Mohler, 2010; Pan \& de la Puente, 2005; Przepiórkowska, 2016). If the evaluation criteria are set to minimize semantic discrepancies detected through back translation, any deviation from the source would be flagged as an inaccuracy, even if the deviation was intentional and meant to make the translated instrument suitable for the target audience.

Dissatisfaction with the back translation method has led survey researchers to depart from it. Back translation is now excluded from the translation guidelines of major survey programs and institutions including the U.S. Census Bureau, the European Social Survey (ESS), and international education assessment studies such as the Programme for International Student Assessment (PISA) of the OECD and the Trends in International Mathematics and Science Study (TIMSS) of International Association for the Evaluation of Educational Achievement (IEA). It has been replaced with a more robust, team-based, multistep forward translation procedure that requires additional pretesting of the translated instrument and thorough documentation of the entire process (Dorer, 2012; Grisay, 2002; Maxwell, 1996; Pan \& de la Puente, 2005). Also, in the health research field, a growing body of literature suggests replacing back translation with a team-based "dual panel" approach (Epstein, Osborne, Elsworth, Beaton, \& Guillemin, 2015; Swaine-Verdier, Doward, Hagell, Thorsen, \& McKenna, 2004). Shortcomings of back translation as a quality-testing tool have also been highlighted by a recent empirical study by Behr (2016). In her comparison of back translation assessment and actual translation assessment by experts, Behr showed that a high number of issues were only detected as a part of actual translation assessment, where back translation yielded false negatives.

Although still widely used, it is becoming apparent that back translation has been losing its validity as a translation quality assessment tool, both theoretically and practically. Some researchers regard back translation as an already obsolete design and some see it in a stage of being abolished as a good practice (for example, see Behr, 2016; Dept, Ferrari, \& Halleux, 2017; and Harkness, Dorer, \& Mohler, 2010). Does this mean that the use of back translation is of little or no value in the process of questionnaire translation? When and how can back translation be useful in cross-cultural survey research?

This paper attempts to advocate the pragmatic value of using back translation as a documentation tool. While back translation is no longer useful as a quality assessment tool, it may nonetheless be useful as a tool for documenting translation negotiations and decisions to make the documentation more informative for all involved researchers and potential readers. Rather than treating detected deviations from the source as inaccuracies to be corrected, back translation can be used to illustrate intentional deviations when it is combined with explanatory 
notes in the documentation. This paper intends to provide some insight on this less-discussed use of back translation in the survey translation literature. The following section summarizes how back translation has been viewed in the translation literature as a tool to demonstrate inevitable differences between the source and the target text. Next a baseline for using back translation as a documentation tool is proposed, with examples of "good" and "bad" back translations. Finally, the value of using back translation will be further demonstrated using examples from recent studies that integrated back translation into their documentation (Pan et al., 2009; Sha, Park, \& Pan, 2012).

\section{Perspectives on back translation as a documentation tool}

\subsection{Using back translation to show the differences that matter}

Unlike the use of back translation as a quality assessment tool to detect discrepancies and mistranslations, the purpose of back translation in the translation literature was to show the inevitable differences between the source and a "well translated" target text. For example, Baker (2011) used back translations to provide readers with some insight into the structure of the translated text, which is never the same as the source text, and to demonstrate difficulties in translating a text into another language and ways of dealing with it. Another example would be Klaudy's (1996) use of back translation as a tool to demonstrate explicitation (addition) strategies in translation. He showed that the word count of a Hungarian literary text was significantly increased when the text was translated into English and then back-translated into Hungarian. This shows how the translation is different from the original source text due to the linguistic and cultural differences between the source and target languages and cultures, and how those differences were retained even when the target language text was translated back into its original language. These studies exemplify the use of back translation as an indicator of the inevitable differences between the source and the translated text, rather than as an error-detector.

In the professional survey translation industry, where translators are often requested to provide translation which will be back-translated later for evaluation, or to provide a back-translation of someone else's translation for that purpose, two articles give valuable insight on how back translation could be more useful when it is used as a tool to explain differences. In Paegelow's (2008) discussion of how to deal with clients' back translation requests as part of translation validation, he drew an important distinction between "differences that matter" (which should be the focus) and "differences that do not", as revealed through back translation. These latter differences may be negligible because they may be due to preferences for certain words but create no difference in meaning. If back translation is used as a quality assessment tool, the focus should be on the differences that matter to correct errors. From the perspective of using back translation as a documentation tool, the differences that matter may be the result of adaptation decisions that need to be explained and documented. Back translation can enhance the documentation of translation decisions by showing "what the translation says."

Another industry perspective worth noting came from Ozolins' (2009) experience of communicating with a translation coordinator and a back translator to reconcile discrepancies between the source and the translation. He observed that back translation gave translators opportunities to explain to clients why the translation had to be that way and why deviations were necessary to make the translation meaningful. Back translation can be used "as a means of giving translators a voice" (Ozolins, 2009, p.1) to facilitate communication between the 
translator and the translation coordinator/survey designer who does not understand the target language and culture, when the translator needs to justify translation choices which might entail a deviation from the source.

Indeed, at its birth as a quality assessment tool in survey translation, back translation was introduced as a solution to the need for researchers to understand the instrument when it is translated into languages unfamiliar to them (Brislin, 1984; Harkness \& Schoua-Glusberg, 1998). Since relatively few people can fluently comprehend several languages, using back translation as an intercultural communication tool has continued to be a common practice when researchers and readers have to deal with multilingual texts. With the growing number of crosscultural and multilingual surveys in the recent years, the number of languages to be translated can be expected to exceed the linguistic capabilities of the survey authors or researchers who lead the translation procedure.

In such studies, it is important to communicate translation decisions in the language that survey authors or researchers can understand, to ensure the adaptation still measures the same construct. When thorough documentation is required for multistep translation procedures, everything that leads to negotiations, making choices, or intentional deviations regarding the source material needs to be recorded and explained (Behr, 2016; Harkness, 2003; Harkness, Dorer, \& Mohler, 2010). Back translation which does not attempt to evaluate translation quality but rather limits its purpose to showing "what the translation says" can be used as a tool to enhance such documentation. While back translation cannot replace any explanation or justification necessary to good documentation by itself, it can serve as an additional documentation tool by describing what the translated term would mean, in the language that survey authors or researchers can understand. In order for the documentation to be informative for all involved (e.g., researchers and potential readers), it is best to provide back translation of the items where the differences matter, with explanations.

\subsection{Back translation that is helpful for documentation: a baseline}

Behr and Shishido (2016) considered a good-practice translation methodology to include a team-based, multistep forward translation approach. This approach highlights the collaboration of a team of experts in translation, subject matter, and survey methodology and the need for assessing the quality and cultural adequacy of the translation. In this approach, translation issues are often identified through expert review and pretesting. While apparent translation issues such as mistranslations, grammatical errors or typos can be easily corrected during translation review, some issues call for adaptation to adequately deliver the intended meaning to the target audience. The difference between the two translation versions (i.e., the original vs. the revised) will be the differences that matter, which need to be well-documented for explanatory purposes or for justifying the translation decisions. If such documentation accompanies back translation, it will benefit the survey designers or researchers who do not speak the language by forming a sense of confidence about the likely adequacy or accuracy (Sha \& Roller, 2016). Furthermore, it will also benefit readers of the documentation who may encounter similar translation challenges either in the same target language or in other languages.

Unlike back translation used as a quality assessment tool, back translation as a documentation tool does not need to be provided by a second translator who is blind to the source material and has no prior knowledge of the project or the survey in question. Rather, to ensure the integrity of the documentation, back translation is better performed by the person responsible for documenting the entire translation process. A (leading) member of the translation expert panel who 
is well aware of the intent of the survey questions, and has the language sensitivity to identify adaptation needs, will be best suited to that role.

Back translation when used as a documentation tool should be able to capture the differences between the source language text and the target language text, or the differences between the two translation versions (i.e., the original vs. the revised/proposed), even when they are very subtle. In order to be informative as a documentation tool, back translation should be literal so it does not add or omit any meaning from the translation in question. At the same time, it should be explanatory to the point that it can capture the difference in meaning in its fullest sense between the source and the target version, or between translation versions.

To illustrate this concept, Table 1 shows "good" and "bad" examples of back translation in documentation, adapted from Sha, Park, and Pan's (2012) cognitive testing of Chinese and Korean versions of the language assistance guide to be used for American Community Survey (ACS). In this study, cognitive interviews ${ }^{1}$ were conducted in the target language, but interviewers were required to write the interview summary reports in English with specific quotes in the target language.

The examples shown in Table 1 illustrate possible responses from a Chinese and a Korean respondent when asked which of the two translated terms would be more suitable to describe themselves: 中国人 vs. 华人 for Chinese and 한국인 vs. 한국계 for Korean. In each language either term could be "correct", but the context may indicate the choice of one as being more appropriate choice than the other; accordingly researchers sought to obtain monolingual respondents' feedback by showing them both versions of the translation.

Table 1: Back translation for documentation, "Good" and "Bad"a

\begin{tabular}{|c|c|c|}
\hline & Chinese & Korean \\
\hline & $\begin{array}{l}\text { Let's look at two terms for "Chinese": } \\
\text { 中国人 vs. 华人. Who do you think } \\
\text { would identify him/herself as 中国人vs. } \\
\text { 华人? }\end{array}$ & $\begin{array}{l}\text { Let's look at two terms for "Korean": } \\
\text { 한국인 vs. 한국계. Who do you think } \\
\text { would identify him/herself as 한국인 vs. } \\
\text { 한국 계? }\end{array}$ \\
\hline $\begin{array}{l}\text { "Bad" } \\
\text { Back } \\
\text { Translation }\end{array}$ & $\begin{array}{l}\text { The respondent said he would be 中国人 } \\
\text { (Chinese) because he is from China. For } \\
\text { people from Taiwan or Singapore, maybe } \\
\text { 华人 (Chinese) is better. He also often } \\
\text { heard the phrase 海外华人 (overseas } \\
\text { Chinese) to mean Chinese in general. }\end{array}$ & $\begin{array}{l}\text { The respondent said he would choose } \\
\text { 한국 계 (Korean) to describe himself } \\
\text { because he was born here and both of his } \\
\text { parents are 한국인 (Koreans). 한국 인 } \\
\text { (Korean) does not sound right for him } \\
\text { because he is an American. }\end{array}$ \\
\hline $\begin{array}{l}\text { "Good" } \\
\text { Back } \\
\text { Translation }\end{array}$ & $\begin{array}{l}\text { The respondent said he would be } \\
\text { 中国人 (person from China) because he } \\
\text { is from China. For people from Taiwan or } \\
\text { Singapore, maybe 华人 (pan-Chinese } \\
\text { person) is better. He also often heard the } \\
\text { phrase 海外华人 (overseas Chinese } \\
\text { person) to mean Chinese in general. }\end{array}$ & $\begin{array}{l}\text { The respondent said he would choose } \\
\text { 한국계 (Korean descent) to describe } \\
\text { himself because he was born here and both } \\
\text { of his parents are 한국인 (Korean } \\
\text { nationals). 한국인 (Korean national) } \\
\text { does not sound right for him because he is } \\
\text { an American. }\end{array}$ \\
\hline
\end{tabular}

a The examples in this table are 'mock-up' quotes. Chinese examples are from Sha \& Roller (2016), which is adapted from Sha, Park, and Pan (2012). Korean quotes are made up for this paper to provide examples parallel to the Chinese examples.

\footnotetext{
1 "Cognitive interview" is a method that aims to reveal respondents' thought process by asking them to "think aloud" about how they understand the survey questions and how they came up with answers. Because these interviews provide important means of finding out directly from respondents about their problems with the questionnaire wordings, this method is widely used for pretesting a draft version of translated survey materials. For details, see Willis (2004), U.S. Census Bureau (2003), and Pan and de la Fuente (2005).
} 
In the "bad" examples, the back translations are not manifestly wrong, but rather fail to differentiate between the two competing terms. By reading the entire quotes, those who do not understand the respective languages may still be able to discern which translated version is preferred by each group of, but will lack a clear understanding of that preference. The differences are only visible to those who understand the target languages. In comparison, the back translations shown in the "good" example provide readers with rich information about how each translated term was perceived differently by the respondent. For example, while the English word "Chinese" can refer to any ethnic Chinese person regardless of where he or she is from, the translation 中国人 refers to a person from mainland China and the translation 华人 encompasses any ethnic Chinese person who might live in or come from China, Taiwan, or Hong Kong.

When back translation is used properly, it can be informative in revealing how competing translated terms are different and why these are perceived differently. "Good" back translations are literal and overt in the sense that they do not add any meaning that was not conveyed in the translated terms, but at the same time they help readers who do not know the language to understand how they are different.

\section{Examples of back translation used for documentation}

When back translation is used as a documentation tool, it does not interfere with the target language translation itself, nor does it replace justification of the translation choices. In other words, when used for documentation, the only purpose of back translation is to show "what the translation says". This simple purpose, however, is valuable in understanding how the target text evolved throughout the translation and assessment process, and was negotiated and finalized.

This section presents three cases that demonstrate the value of back translation as a documentation tool. The examples come from two published studies that pretested the translation of the 2010 Census questionnaires (Pan et al., 2009) and the American Community Survey (ACS) language assistance guides (Sha, Park, \& Pan, 2012). In the study of 2010 Census questionnaires (Pan et al., 2009), translation of four non-English languages - Chinese, Korean, Vietnamese, and Russian - as well as English draft version were tested. In the study of the language assistance guides for the American Community Survey (Sha, Park, \& Pan, 2012), Chinese and Korean versions of the instrument were tested. In both studies, translation of survey materials followed the U.S. Census Bureau's guideline for translation of data collection instruments described by Pan and de la Fuente (2005). A panel of language experts, led by a bilingual survey methodologist, was formed for each language based on translation expertise, familiarity with survey materials and contents, and bicultural competency as selection criteria. The team members worked together in close cooperation from translation review through to finalization of the translated version, performing expert review, recruiting monolingual interview participants, conducting in-depth cognitive pretesting interviews, writing interview summary reports in English with specific quotes in the target language, and participating in debriefing of results. All documentations, including back translations, reported in these studies were written by each language team lead. (For more details, see the methodology chapter of Pan et al., 2009, and also Sha, Park, \& Pan, 2012). These studies were selected because they provide comprehensive documentation of the translation 
process with rich examples in both the translated and back-translated version of source language terms.

\subsection{Case 1. Illustrating how the translation has evolved throughout the process}

Survey translation is a constant decision-making process and the translation of a term or a concept may change over the course of different stages of the translation process. Back translation can illustrate this evolving property of translation by comparing what the initial version said as compared to the finalized version.

Table 2 traces the development of how an answer category ("relatives, such as adult children, cousins, or in-laws") was translated into Korean: initial translation, revised translation recommended by a team of reviewers, and final translation resulting from cognitive pretesting with Korean monolingual speakers living in the United States (Pan et al., 2009). The back translations in Table 2 are informative because they are literal enough to capture the differences and subtleties among the three versions. For instance, the unnaturalness of the rendering of "adult children" in the initial translation is reflected in its back translation, "being grown-up children". In the revised and final translations, the back translation shows how the newer version is different from the previous version. Pan and her colleagues (2009) explained in detail how and why the translations were revised and improved upon each revision. For example, the report documented that the revised translation simplified the initial translation of "in-laws", revised the unnatural translation of "adult children", and rearranged the sentence. However, cognitive pretesting with Korean monolingual speakers, who are potential respondents of the questionnaire, revealed that it is more natural to combine "relatives" and "in-laws" in the Korean language. Based on the monolingual participants' feedback, the translation was revised again. Coupled with back translations, these detailed explanations on translation decisions provided complete documentation.

Table 2. Evolution of Translation: A Korean Example ${ }^{a}$

\begin{tabular}{l|l}
$\begin{array}{l}\text { Source Text Answer } \\
\text { Category }\end{array}$ & Relatives, such as adult children, cousins, or in-laws \\
\hline $\begin{array}{l}\text { Initial Translation and } \\
\text { Back Translation }\end{array}$ & $\begin{array}{l}\text { 성장한 자녀, 사촌 또는 혼인에 의한 인척 (in-laws) 등의 친척 } \\
\text { Relatives such as being grown-up children, cousins or in-laws (in-laws) by } \\
\text { marriage [(in-laws) in English] }\end{array}$ \\
\hline $\begin{array}{l}\text { Revised Translation and } \\
\text { Back Translation } \\
\text { (After Expert Review) }\end{array}$ & $\begin{array}{l}\text { 성인 자녀 또는 사촌 등의 친척 또는 인척 } \\
\text { Relatives or in-laws such as adult children or cousins }\end{array}$ \\
\hline $\begin{array}{l}\text { Final Translation and } \\
\text { Back Translation } \\
\text { (After Pretesting) }\end{array}$ & $\begin{array}{l}\text { 성인 자녀, 또는 사촌 등의 친인척 } \\
\text { Adult children, or relatives/in-laws such as cousins }\end{array}$
\end{tabular}

${ }^{\text {a }}$ From Pan, Sha, Park, \& Schoua-Glusberg (2009, p. 68. 88)

\subsection{Case 2. Aid to illustrate how the final translation choice was made among competing translation candidates}

A "correct" yet high-register term does not always work as intended in a translated survey questionnaire. When such a term is not in common use among the target audience, survey respondents may not understand the question. For example, as shown in Table 4, the word 失联 (loss of hearing intelligence) was used as the Chinese translation of "deaf". During cognitive pretesting, Chinese monolingual participants suggested that 失联 was not understood by everyone, and consequently the translation was revised to say 耳狵 (ear deaf). The revised term is commonly used, even if it may be more vernacular (Sha, Park, \& Pan, 
2012, p. 119). The negotiation should aim for using a more vernacular term in order to accommodate the cognitive process of the target respondents, in this case the monolingual Chinese speakers living in the US. The back translations shown in Table 3 attempt to show the flaws in the translation by trying to convey how the translated text would sound to its readers. The additional justification completes the documentation, providing the reasons why the revised translation had to be that way.

Table 3. Choosing Chinese Translation for "Deaf"

\begin{tabular}{|c|c|c|c|}
\hline Source Text & Original Translation & $\begin{array}{l}\text { Proposed } \\
\text { Translation }\end{array}$ & Justification \\
\hline $\begin{array}{l}\text { Is this person } \\
\text { deaf or does } \\
\text { he/she have } \\
\text { serious } \\
\text { difficulty } \\
\text { hearing? }\end{array}$ & $\begin{array}{l}\text { 这个人是否失聪, } \\
\text { 或者有严重的听力 } \\
\text { 障碍? } \\
\text { Does this person have } \\
\text { loss of [hearing] } \\
\text { intelligence or does } \\
\text { he/she have serious } \\
\text { difficulty hearing? }\end{array}$ & $\begin{array}{l}\text { 这个人是否耳聋, } \\
\text { 或者有严重的听力 } \\
\text { 障碍? } \\
\text { Is this person ear deaf } \\
\text { or does he/she have } \\
\text { serious difficulty } \\
\text { hearing? }\end{array}$ & $\begin{array}{l}\text { Some respondents in the first round did } \\
\text { not know the initial translation } \\
\text { 失联 meant deaf; instead, they only } \\
\text { knew its literal meaning, which was loss } \\
\text { of intelligence. This might be a high- } \\
\text { level vocabulary word, and we } \\
\text { recommended using a vernacular term } \\
\text { instead: 耳娏 (ear deaf). This change } \\
\text { worked well in the second round. }\end{array}$ \\
\hline
\end{tabular}

\subsection{Case 3. Illustrating how the term was adapted when there was no equivalent concept in the target language}

When there is no equivalent translation for a source language concept, the translation team often employs adaptation strategies to convey the intended meaning. Sometimes the adaptation is done by using a concept comparable to the one that the source version tries to measure. Alternatively, it is sometimes done by using the "explicitation strategy", i.e., making what is implicit in the source text explicit in the translation by adding descriptive or explanatory words or phrases (Klaudy, 1996).

One example is the translation of "foster children" into Chinese and Korean. The term "foster children" refers to children in the US-specific, governmentsponsored, foster-care program. Thus "foster" is not to be understood here in its general meaning (i.e. taking care of a child who is not one's own), but in a more restricted sense that will be implicit to English-language readers in the US. As shown in Table 4, the initial translations into both Chinese and Korean ignored what was implicit in the source, and used expressions that refer to a situation of taking care of another's children generally. As documented in Pan et al., (2009), the Korean translation used the word 위탁 (consigned), referring to a situation of being temporarily given to someone for being cared for or supervised, and the Chinese translation used the word 寄养 (being taken care of), which is common practice between close friends or relatives in China. When the original translations were empirically tested with Korean and Chinese speakers in the United States, most of them did not understand the concept in the original translation: the Korean respondents did not understand a situation that a child might be "consigned" to someone while the Chinese respondents understood it as the practice known from their home country, i.e., taking care of a child on behalf of a friend or a relative out of goodwill. The solution for both languages was to adapt the translation by adding a word "government" to make it explicit that this is a governmentsponsored program. These adaptation strategies were documented using explanatory prose and back translation.

In addition, the examples also showed that a translation strategy used for one language could be applied to another language when the translators harmonize the translation. Pan et al. (2009) explained that the proposed Chinese translation 
discarded the original translated term 寄养 (being taken care of) because it is associated with a common child-rearing practice between friends. Instead, they replaced it with 委托 (given for temporary care (through official process)), inspired by the Korean translation of "foster". This exemplifies how a back translation can be used to exchange ideas and models between languages.

Table 4. Adaptation of "Foster Children" in Korean and Chinese Using an Explicitation Strategy ${ }^{\mathrm{a}}$

\begin{tabular}{l|l|l|l} 
Language & $\begin{array}{l}\text { Original } \\
\text { translation }\end{array}$ & $\begin{array}{l}\text { Proposed } \\
\text { translation }\end{array}$ & Justification \\
\hline \multirow{3}{*}{ Korean } & $\begin{array}{l}\text { 위탁아 } \\
\text { (Consigned } \\
\text { children) }\end{array}$ & $\begin{array}{l}\text { 정부 위탁아 } \\
\text { (Government- } \\
\text { consigned } \\
\text { children) }\end{array}$ & $\begin{array}{l}\text { Most respondents did not understand the meaning } \\
\text { of foster children from the current translation } \\
\text { because the concept does not exist in Korea. We } \\
\text { recommend adding a short description to convey } \\
\text { the meaning of foster program sponsored by the } \\
\text { government. }\end{array}$ \\
\hline \multirow{5}{*}{ Chinese } & $\begin{array}{l}\text { 寄养的儿童 } \\
\text { (Children under } \\
\text { care } \\
\text { [temporary and } \\
\text { at a } \\
\text { relative or } \\
\text { friend's]) }\end{array}$ & $\begin{array}{l}\text { 政府委托寄养 } \\
\text { 的孩子 } \\
\text { (Children under } \\
\text { government- } \\
\text { sponsored } \\
\text { care) }\end{array}$ & $\begin{array}{l}\text { The current translation does not capture the } \\
\text { intended meaning of the original concept. It means } \\
\text { "children under the temporary care of one's } \\
\text { relatives and friends." We propose to use a } \\
\text { descriptive phrase to convey this concept because } \\
\text { there is no equivalent term in Chinese. }\end{array}$
\end{tabular}

${ }^{\text {a }}$ From Pan, Sha, Park \& Schoua-Glusberg (2009, p. 50. 88)

\section{Discussion and conclusion}

When back translation is mentioned in the context of cross-cultural and multilingual surveys, its purpose, almost without exception, is to assess the quality of translation by comparing the back translation with the source text (Harkness \& Schoua-Glusberg, 1998). Using back translation for that purpose is still a common practice, but is no longer considered a good practice.

This paper argues that back translation can be more useful as a documentation tool that supports explanatory prose justifying translation decisions. A "good" back translation then is one that shows, to the extent possible, the differences between the source text and the translation/adaptation or between the different translated versions of the same text. The approach is not intended to check the quality of the translation but instead to enhance the documentation of translation decisions, and also to promote harmonizing translations between languages. The three cases cited from two publicly available studies show that back translation can be used to illustrate how a translation has transformed throughout the translation process, and how the translators adapted the translation to communicate the spirit of the source text when there was no equivalent translation term for a source language concept.

Furthermore, back translation can be used to enhance communication among questionnaire designers and translators to ensure that adaptations and tailoring efforts used in the translation are appropriate and that the translation is suitable to measure the equivalent concept. Back translation not only shows "what the translation says," but traces how the translation was modified, negotiated, and finalized. Translation is a constant decision-making process and the translation of a term or a concept may improve over the course of different stages of the translation process. Back translation can illustrate this evolutionary property of 
translation by comparing what the initial version said with translations revised by a reviewer or through empirical assessment such as cognitive pretesting.

As Behr and Shishido (2016) suggest, comprehensive documentation helps to inform later steps in the translation process, thus making the entire translation process more efficient. In order to maximize the value of back translation, ideally, the documentation would be complete with the source text, original and revised translations and their corresponding back translations, and adaptation notes or justifications that explain why the revision was necessary and how it improved the original translation. Comprehensive documentation like this gives readers, in particular stakeholders or decision-makers who do not speak the language of the translation, a level of confidence about the quality of the translation. For example, the source text can be used as a reference point and the back translations used to follow how the translation versions were developed and finalized. Back translation should not, however, replace explanatory prose that documents, explains or justifies translation decisions. Future research would benefit from including back translation as part of the documentation process of the adaptation of survey items into multiple languages. On a pragmatic side, continuing efforts to formulate preconditions and conditions for obtaining good back translations would also benefit the multilingual survey research community.

With the growing amount of large-scale, cross-cultural research that involves multiple languages, the use of back translation in documentation seems to be an ongoing practice. This is illustrated by the presence of publicly available studies that report on it, some of which were used as examples in this paper (Leeman, 2015; Pan, Sha, Park, \& Schoua-Glusberg, 2009; Sha \& Lai, 2016; Sha, Park, \& Pan, 2012). However, the existing literature does not explicitly discuss this utility. Epstein and his colleagues (Epstein, Santo, \& Guillemin, 2015) once suggested that back translation would find a better use as a communication tool with the author(s) of the questionnaire. This paper has attempted to shed light on this lessdiscussed use of back translation in survey work.

\section{Acknowledgement}

The main idea of this paper was originally inspired by Mandy Sha and I would like to express special thanks to her.

\section{References}

Acquadro, C., Conway, K., Hareendran, A., Aaronson, N., \& Issues, E. R. (2008). Literature review of methods to translate health-related quality of life questionnaires for use in multinational clinical trials. Value in Health, 11(3), 509-521.

Baker, M. (2011). In other words: A coursebook on translation. Routledge.

Behr, D. (2016). Assessing the use of back translation: The shortcomings of back translation as a quality testing method. International Journal of Social Research Methodology, 20:6, 573-584. DOI: 10.1080/13645579.2016.1252188.

Behr, D., \& Shishido, K. (2016). The translation of measurement instruments for crosscultural surveys. In C. Wolf, D. Joye, T. Smith, \& Y.-C. Fu (Eds.), The SAGE handbook of survey methodology.

Brislin, R. W. (1970). Back-translation for cross-cultural research. Journal of CrossCultural Psychology, 1(3), 185-216.

Brislin, R. W. (1984). Wording and translation in research instruments. In Lonner, W. \& Berry, J. (Eds.), Field methods in cross-cultural research (pp. 137-164). Newbury Park, CA: Sage 
Chidlow, A., Plakoyiannaki, E., \& Welch, C. (2014). Translation in cross-language international business research: Beyond equivalence. Journal of International Business Studies, 45(5), 562-582.

Dept, S., Ferrari, A., \& Halleux, B. (2017). Translation and cultural appropriateness of survey material in large-scale assessments. In Lietz, P., Cresswell, J. C., Rust, K. F., \& Adams, R. J. (Eds.), Implementation of large-scale education assessments (pp. 153-172). John Wiley \& Sons.

Dorer, B. (2012). ESS Round 6 Translation Guidelines. Mannheim: European Social Survey, GESIS.

Douglas, S. P., \& Craig, C. S. (2007). Collaborative and iterative translation: An alternative approach to back translation. Journal of International Marketing, 15(1), 30-43.

Epstein, J., Osborne, R. H., Elsworth, G. R., Beaton, D. E., \& Guillemin, F. (2015). Crosscultural adaptation of the Health Education Impact Questionnaire: Experimental study showed expert committee, not back-translation, added value. Journal of Clinical Epidemiology, 68(4), 360-369.

Epstein, J., Santo, R. M., \& Guillemin, F. (2015). A review of guidelines for cross-cultural adaptation of questionnaires could not bring out a consensus. Journal of Clinical Epidemiology, 68(4), 435-441.

Hagell, P., Hedin, P. J., Meads, D. M., Nyberg, L., \& McKenna, S. P. (2010). Effects of method of translation of patient-reported health outcome questionnaires: A randomized study of the translation of the Rheumatoid Arthritis Quality of Life (RAQoL) Instrument for Sweden. Value in Health, 13(4), 424-430.

Harkness, J. A. (2003). Questionnaire translation. In Harkness, J. A., van de Vijver, F. J., Mohler, P. P., \& Wiley, J. (Eds.), Cross-cultural survey methods (pp. 35-56). Hoboken, NJ: Wiley-Interscience.

Harkness, J. A., Villar, A., \& Edwards, B. (2010). Translation, adaptation, and design. In Harkness, J. A., Braun, M., Edwards, B., Johnson, T. P., Lyberg, L., Mohler, P. P., Smith, T. W. (Eds.), Wiley series in survey methodology. Survey methods in multinational, multiregional, and multicultural contexts (pp. 115-140). Hoboken, NJ: John Wiley \& Sons Inc. .

Harkness, J., \& Schoua-Glusberg, A. (1998). Questionnaires in translation. In Harkness, J. (Ed.), Cross-cultural survey equivalence (pp. 87-126). Manheim: ZUMANachrichten Spezial 3. Retrieved from http://nbn-resolving.de/urn:nbn:de:0168ssoar-49733-1

Harkness, J., Dorer, B \& Mohler, P. (2010). Translation: Assessment. In Guidelines for best practice in cross-cultural surveys. Ann Arbor, MI: Survey Research Center, Institute for Social Research, University of Michigan. Retrieved from http://www.ccsg.isr.umich.edu

Harkness, J., Villar, A., Kephart, K., Behr, D., \& Schoua-Glusberg, A. (2009). Research on translation assessment procedures: Back translation and expert review. Paper presented at the International Workshop on Comparative Survey Design and Implementation. Ann Arbor, MI.

Klaudy, K. (1996). Back-translation as a tool for detecting explicitation strategies in translation. In Klaudy, K., Lambert, J., \& Sohár, A. (Eds.), Translation studies in Hungary (pp. 99-114). Budapest: Scholastica, .

Lee, C. C., Li, D., Arai, S., \& Puntillo, K. (2009). Ensuring cross-cultural equivalence in translation of research consents and clinical documents: A systematic process for translating English to Chinese. Journal of Transcultural Nursing, 20(1), 77-82.

Leeman, J. (2015). Cognitive testing of the American Community Survey Language Question in Spanish. Survey Methodology, 2015-02.

Maxwell, B. (1996). Translation and cultural adaptation of the survey instruments. Third international mathematics and science study (TIMSS) technical report, 1, 159-169.

Ozolins, U. (2009). Back translation as a means of giving translators a voice. Translation \& Interpreting, 1(2), 1-13.

Paegelow, R. S. (2008). Back Translation Revisited: Differences that Matter (and Those that Do Not). The ATA Chronicle, 1, 22-25. 
Pan, Y., \& de la Puente, M. (2005). Census Bureau guideline for the translation of data collection instruments and supporting materials: Documentation on how the guideline was developed. Survey Methodology, 6. Retrieved from https://www. census.gov/srd/papers/pdf/rsm2005-06.pdf.

Pan, Y., \& Fond, M. (2014). Evaluating multilingual questionnaires: A sociolinguistic perspective. Survey Research Methods, 8(3), 181-194.

Pan, Y., Sha, M., Park, H., \& Schoua-Glusberg, A. (2009). 2010 Census Language Program: Pretesting of Census 2010 questionnaire in five languages. Survey Methodology, 2009-01. Statistical Research Division Research Report Series. Prepared for the U.S. Census Bureau. Retrieved from http://www.census.gov/srd/ papers/pdf/rsm2009-01.pdf

Przepiórkowska, D. (2016). Translation of questionnaires in cross-national social surveys: A niche with its own theoretical framework and methodology. Między Oryginatem a Przektadem, 31, 121-135.

Sha, M. \& Roller, M. (2016) Pretesting Multilingual Questionnaires: Achieving Quality Outcomes Using Qualitative Methods. Paper presented at the Midwest Association for Public Opinion Research (MAPOR), Methods and Substance Webinar Series, Chicago, IL.

Sha, M., \& Lai, J. (2016). A case study of improving and evaluating consumer survey translation. Translation \& Interpreting, 8(1), 86-100.

Sha, M., Park, H., \& Pan, Y. (2012). Translation review and cognitive testing of American Community Survey (ACS) language assistance guides in multiple languages. Census Bureau Working Papers Series. Retrieved from https://www.census.gov/content/dam/ Census/library/workingpapers/2012/acs/2012_Sha_01.pdf

Swaine-Verdier, A., Doward, L. C., Hagell, P., Thorsen, H., \& McKenna, S. P. (2004). Adapting quality of life instruments. Value in health, 7, S27-S30.

U.S. Census Bureau. (2003) Census Bureau Standard: Pretesting questionnaire and related materials for surveys and censuses. Methodology and Standards Directorate. U.S. Census Bureau, U.S. Department of Commerce, Washington, D.C. Available online at https://www.census.gov/srd/pretest-standards.pdf

Willis, G. B. (2003) Cognitive interviewing: A tool for improving questionnaire design. Thousand Oaks, CA: Sage Publications. 